\title{
Centrilobular emphysema and coronary artery calcification: mediation analysis in the SPIROMICS cohort
}

Surya P. Bhatt ${ }^{1,2^{*}}$ D, Hrudaya P. Nath ${ }^{2,3}$, Young-il Kim ${ }^{1,4}$, Rekha Ramachandran ${ }^{4}$, Jubal R. Watts ${ }^{3}$, Nina L. J. Terry ${ }^{3}$, Sushil Sonavane ${ }^{3}$, Swati P. Deshmane ${ }^{3}$, Prescott G. Woodruff $f^{5}$, Elizabeth C. Oelsner ${ }^{7}$, Sandeep Bodduluri, ${ }^{1,2}$, MeiLan K. Han ${ }^{8}$, Wassim W. Labaki ${ }^{8}$, J. Michael Wells ${ }^{1,2,6}$, Fernando J. Martinez ${ }^{9}$, R. Graham Barr ${ }^{7}$, and Mark T. Dransfield ${ }^{1,2,6}$ for the SPIROMICS investigators

\begin{abstract}
Background: Chronic obstructive pulmonary disease (COPD) is associated with a two-to-five fold increase in the risk of coronary artery disease independent of shared risk factors. This association is hypothesized to be mediated by systemic inflammation but this link has not been established.

Methods: We included 300 participants enrolled in the SPIROMICS cohort, 75 each of lifetime non-smokers, smokers without airflow obstruction, mild-moderate COPD, and severe-very severe COPD. We quantified emphysema and airway disease on computed tomography, characterized visual emphysema subtypes (centrilobular and paraseptal) and airway disease, and used the Weston visual score to quantify coronary artery calcification (CAC). We used the Sobel test to determine whether markers of systemic inflammation mediated a link between spirometric and radiographic features of COPD and CAC.
\end{abstract}

Results: $\mathrm{FEV}_{1} / \mathrm{FVC}$ but not quantitative emphysema or airway wall thickening was associated with CAC $(p=0.036)$, after adjustment for demographics, diabetes mellitus, hypertension, statin use, and CT scanner type. To explain this discordance, we examined visual subtypes of emphysema and airway disease, and found that centrilobular emphysema but not paraseptal emphysema or bronchial thickening was independently associated with CAC $(p=0.019)$. MMP3, VCAM1, CXCL5 and CXCL9 mediated 8, 8,7 and 16\% of the association between FEV $1 /$ FVC and CAC, respectively. Similar biomarkers partially mediated the association between centrilobular emphysema and CAC.

Conclusions: The association between airflow obstruction and coronary calcification is driven primarily by the centrilobular subtype of emphysema, and is linked through bioactive molecules implicated in the pathogenesis of atherosclerosis.

Trial Registration: ClinicalTrials.gov: Identifier: NCT01969344.

Keywords: Emphysema, COPD, Coronary artery calcification, Cardiovascular disease, Mediators

\footnotetext{
* Correspondence: sbhatt@uabmc.edu

${ }^{1}$ Division of Pulmonary, Allergy and Critical Care Medicine and Lung Health

Center, University of Alabama at Birmingham, THT 422, 1720, 2nd Avenue

South, Birmingham, AL 35294, USA

${ }^{2} \cup A B$ Lung Imaging Core, University of Alabama at Birmingham,

Birmingham, AL 35294, USA

Full list of author information is available at the end of the article
}

(c) The Author(s). 2018 Open Access This article is distributed under the terms of the Creative Commons Attribution 4.0 International License (http://creativecommons.org/licenses/by/4.0/), which permits unrestricted use, distribution, and reproduction in any medium, provided you give appropriate credit to the original author(s) and the source, provide a link to the Creative Commons license, and indicate if changes were made. The Creative Commons Public Domain Dedication waiver (http://creativecommons.org/publicdomain/zero/1.0/) applies to the data made available in this article, unless otherwise stated. 


\section{Introduction}

Chronic obstructive pulmonary disease (COPD) is associated with a two-to-five fold increase in the risk of coronary artery disease $[1,2]$ and epidemiologic studies indicate that this relationship is independent of shared risk factors such as age and cigarette smoking $[1,2]$. The magnitude of risk of cardiac disease associated with low lung function is similar to the population-attributable risk conferred by well-established cardiac risk factors such as hypertension and diabetes mellitus, suggesting that COPD is a proatherogenic condition [3]. Multiple studies have shown associations between low lung function and CT emphysema with measures of endothelial dysfunction and atherosclerosis including brachial flow-mediated dilation, [4] carotid intima-medial thickness, [5] arterial stiffness, $[6,7]$ and coronary artery calcium (CAC) $[8,9]$ and though some have also suggested a dose-response relationship $[10,11]$ the underlying mechanistic links are not clear.

The most accepted hypothesis for the link between COPD and atherosclerosis is that chronic inflammation in the lungs results in systemic inflammation and contributes to an atherogenic milieu [12]. The systemic inflammation observed in other chronic diseases is associated with atherosclerosis, [13] and it is plausible that it is the prime driver of coronary artery disease in COPD. However, studies examining the link between poor lung function and systemic inflammation have demonstrated conflicting results or weak to modest correlations $[6,7,10,14-16]$. No single study has assessed a three-way link between airflow obstruction, systemic inflammation and coronary artery disease in COPD, and no specific mediators of these associations have been identified. COPD includes both emphysema and airway disease, and it is not known if these structural phenotypes are differentially associated with systemic inflammation and atherosclerosis, and whether this underlies the poor correlations reported.

We analyzed data from the Subpopulations and intermediate outcome measures in COPD study (SPIROMICS) and hypothesized that the severity of airflow obstruction would be directly associated with coronary artery disease as assessed by CAC. We also hypothesized that emphysema subtypes and airway disease are differentially associated with markers of systemic inflammation which would mediate the link with coronary artery disease.

\section{Methods}

\section{Participants}

We included participants from SPIROMICS, a well characterized cohort of normal subjects (stratum 1), current and former smokers at risk for COPD (stratum 2), with mild-to-moderate COPD as defined by the Global Initiative for Chronic Obstructive Lung Disease (GOLD) recommendations (stratum 3), and with severe-to-very-severe COPD (stratum 4) [17]. The study was approved by the institutional review boards of all eleven participating centers, and all participants provided written informed consent. The first 75 participants who enrolled in each stratum with a full set of biomarker data were included. All participants underwent pre and post bronchodilator spirometry at enrollment according to the American Thoracic Society guidelines. Computed tomography (CT) scans were performed at end inspiration. Physician diagnosed self-reported hypertension, diabetes mellitus, and coronary artery disease (CAD) were recorded. Statin use was defined by patient-reported use of statins in the 3 months prior to enrollment. We used CAC as a surrogate for clinical and subclinical CAD. Compared to cardiovascular risk scores, $\mathrm{CAC}$ is a robust measure of early and subclinical CAD and is also an independent predictor of incident adverse cardiovascular events [18].

\section{Measurement of lung disease}

Airflow obstruction was quantified by the ratio of the post bronchodilator forced expiratory volume in the first second $\left(\mathrm{FEV}_{1}\right)$ to the forced vital capacity (FVC), and the severity of airflow obstruction quantified by $\mathrm{FEV}_{1} \%$ predicted [19]. We measured overall emphysema quantitatively using 3D Slicer software (https://www.slicer.org/) on inspiratory CT with a density mask analysis after segmentation and exclusion of large and medium sized airways, such that voxels < - $950 \mathrm{HU}$ in density were classified as emphysematous [20]. Airway wall thickness was quantified by the Pi10, defined by the square root of the wall area of a theoretical circular cross section of an airway with $10 \mathrm{~mm}$ lumenal perimeter, using an automated algorithm based on the using the optimal surface algorithm (Apollo Software, Vida Diagnostics Inc) $[21,22]$. Five readers (4 radiologists and 1 pulmonologist) visually scored emphysema subtypes and airway disease on lung windows according to the Fleischner Society criteria [23]. Briefly, emphysema subtypes were classified as centrilobular emphysema or CLE (none, trace, mild, moderate, confluent and advanced destructive) and paraseptal emphysema or PSE (none, mild, substantial). The presence of any moderate, confluent or advanced destructive CLE was deemed clinically substantial. The presence or absence of airway wall thickening was noted and when present, severity classified as borderline or definite. Definite airway wall thickening was considered clinically significant.

\section{Measurement of potential plasma mediators}

Ten plasma mediators of the link between COPD and CAC were selected a priori representing pathways previously implicated as potential drivers of either disease. Based on plausible biologic pathways, the mediators included were acute phase reactants and cytokines involved in systemic inflammation [C-reactive protein (CRP), fibrinogen, tumor necrosis factor-alpha (TNF- $\alpha$ ) and interleukin-6 (IL-6)], 
chemokines involved in neutrophil activation [C-X-C Motif Chemokine Ligand 5 (CXCL5)], T-cell chemoattractant [C-X-C Motif Chemokine Ligand 9 (CXCL9)], adhesion molecules important in the leucocyte-endothelial interaction [intercellular (ICAM-1) and vascular cell (VCAM-1) adhesion molecules], and matrix metalloproteinases important in emphysema and coronary plaque pathogenesis [MMP3 and MMP9]. Although we had access to a number of additional plasma biomarkers, we did not include these in the analysis to avoid multiple comparisons and false discovery. All plasma mediators were measured using commercially available Myriad RBM "Human InflammationMAP" multiplex assay [24].

\section{Measurement of coronary artery calcification}

High resolution CT scans were performed in all participants and inspiratory scans were used for the visual measurement of CAC. Two readers who were blinded to clinical and quantitative $\mathrm{CT}$ metrics visually analyzed the coronary arteries using mediastinal soft tissue window settings to calculate the Weston visual score for CAC [25]. The Weston score ranges from 0 to 3 for each of the left main, left circumflex, anterior descending and the right coronary arteries as follows: No visually detected calcium $=0$, Only a single high density pixel detected $=1$, Calcium dense enough to cause a blooming artifact $=3$, and Calcium intermediate and between 1 and $3=2$. The total score ranges from 0 to 12 . The Weston score on non-gated scans correlates well with Agatston scores measured on electrocardiographically gated CT scans [26]. We excluded participants who had undergone coronary artery bypass grafting.

\section{Statistical analyses}

Distributions of continuous variables were tested and log transformations were performed for emphysema, CAC and plasma mediators. Pearson's correlation was used to test correlations between $\mathrm{FEV}_{1} / \mathrm{FVC}$, Pi10, log emphysema, the log of plasma mediators and $\log$ CAC. A sample size of 300 patients was considered adequate to achieve $88 \%$ power to detect indirect effect size of 0.04 or larger when direct effect is 0.1 and total effect is 0.14 at significance level of alpha $=0.05$. The power of the test of the indirect effect was prepared by using the joint test of significance [27]. Intra- and inter-rater agreement were calculated for continuous and categorical CT parameters using intra-class correlation coefficient and multi-rater kappa, respectively. Univariate and multivariable associations between airflow obstruction (post bronchodilator $\mathrm{FEV}_{1} / \mathrm{FVC}$ ) and $\log \mathrm{CAC}$ were tested with adjustment for age, gender, race, body-mass-index (BMI), pack-years of smoking, current smoking status, diabetes mellitus, hypertension, statin use, and CT scanner type using generalized linear regression models.
Similarly, multivariable associations between quantitative $\log$ emphysema and $\log \mathrm{CAC}$ were tested with adjustment for age, gender, race, body-mass-index (BMI), postbronchodilator $\mathrm{FEV}_{1}$, pack-years of smoking, current smoking status, diabetes mellitus, hypertension, statin use, and CT scanner type. Similar calculations were repeated for Pi10, emphysema subtypes and the presence of bronchial wall thickening in separate models.

\section{Mediation analysis}

To test whether any of the preselected plasma biomarkers were important in the link between emphysema and $\mathrm{CAC}$, we performed mediation analysis by using three way regression models. The Sobel test was used to determine whether any specific biomarker fully or partially mediated the relationship between $\mathrm{FEV}_{1} / \mathrm{FVC}$ and $\log$ CAC (Additional file 1: Figure S1). The following criteria had to be met for three way regression models for mediation analysis: there existed a significant association between the independent and dependent variable; significant association between the independent variable and the mediator; significant association between the mediator and the dependent variable; and the association between the independent and dependent variables is attenuated when the mediator is added to the regression model. The indirect and direct effects of $\mathrm{FEV}_{1} / \mathrm{FVC}$ on $\log C A C$ were evaluated based on correlation coefficients of $\mathrm{FEV}_{1} / \mathrm{FVC}$ estimated from three way regression models. Sobel test was used to determine if the indirect effect of $\mathrm{FEV}_{1} / \mathrm{FVC}$ was statistically significant. Mediated proportions of the total effect of $\mathrm{FEV}_{1} / \mathrm{FVC}$ were calculated and presented. As the Sobel test assumes normality of variables and that there are no measurement errors, percentile bootstrap confidence intervals were used to test the indirect effect. The accelerated bias-corrected bootstrap estimates correction for a bias in the average estimate and the standard deviation across potential values of the indirect coefficient [28]. Similar analyses were repeated for the association between structural lung disease significantly associated with $\log \mathrm{CAC}$ on multivariable analysis (centrilobular emphysema) and log CAC.

All analyses were performed using IBM SPSS Statistics 24.0 and SAS 9.4 (SAS Institute, Cary, NC). A two-sided alpha level of 0.05 was considered statistically significant for all analyses.

\section{Results}

We included 300 participants, 75 from each stratum with a full set of biomarkers and complete spirometry and CT data. The mean (SD) age was 62.0 (9.6) years, with 36.7 (28.3) pack-years smoking history. 209 (69.7\%) were male, 91 (30.3\%) were African American, and 94 (31.3\%) were current smokers. Kappa values for intra-observer agreement for detecting substantial CLE, 
substantial PSE, and definite airway wall thickening were $0.88 \pm$ SE0.09, $0.54 \pm 0.23$, and $0.53 \pm 0.24$, respectively, and for inter-observer agreement were $0.81 \pm 0.08,0.37$ \pm 0.08 , and $0.33 \pm 0.08$, respectively. There was excellent agreement between readers for CAC, with intra-class correlation coefficient for within and between observers of 0.98 (95\% CI 0.97 to $0.98 ; p<0.001$ ), and 0.96 (95\% CI 0.92 to $0.98 ; p<0.001)$, respectively. Table 1 shows a comparison of baseline characteristics of these participants. Participants with COPD had a greater frequency of CAD than those without COPD $(11.3 \%$ vs. $2.0 \%$; $p=$ 0.002), and those with COPD had a greater CAC score than those without COPD (median 6.0, IQR $25-753.0$ to 10.0 vs. $2.0, \mathrm{IQR}_{25-75} 0$ to $\left.5.0 ; p<0.001\right) .137(45.7 \%)$ had hypertension, $43(14.3 \%)$ had diabetes mellitus, and $121(40.3 \%)$ were on statins. With progressive airflow obstruction across strata, there was greater emphysema as expected, as well as increasing CAC (Jonckheere's trend test $p<0.001$ ).

\section{Spirometric airflow obstruction}

There was a significant association between airflow obstruction $\left(\mathrm{FEV}_{1} / \mathrm{FVC}\right)$ and $\log \mathrm{CAC}$ after multivariable adjustments (Table 2). On univariate analysis, the severity of airflow obstruction ( $\mathrm{FEV}_{1} \%$ predicted) was also associated with $\log \mathrm{CAC}$ (crude $\beta=-0.004 \pm 0.001 ; p<0.001$ ), and this relationship remained significant after multivariable adjustment (adjusted $\beta=-0.001 \pm 0.001 ; p=0.009$ ).

\section{Quantitative emphysema and airway disease}

On univariate analysis, there was a significant association between log emphysema and log CAC (crude regression coefficient $\beta=0.348 \pm 0.064 ; p<0.001$ ). However, after adjustment for age, gender, race, BMI, pack-years of smoking, current smoking status, $\mathrm{FEV}_{1}$, diabetes mellitus, hypertension, statin use, and CT scanner type, this association was no longer significant, adjusted regression coefficient $\beta=-0.074 \pm 0.077 ; p=0.340$ (Table 2). Pi10 was significantly associated with $\log \mathrm{CAC}$ on

Table 1 Comparison of Demographics and Computed Tomography Characteristics of Participants

\begin{tabular}{|c|c|c|c|c|}
\hline & Stratum $1(n=75)$ & Stratum $2(n=75)$ & Stratum $3(n=75)$ & Stratum $4(n=75)$ \\
\hline Age (years) & $54.3(9.5)$ & $59.8(9.3)$ & $64.8(8.5)$ & $64.8(6.7)$ \\
\hline Sex, Male (\%) & $32(42.7 \%)$ & $56(74.7 \%)$ & $64(85.3 \%)$ & $57(76.0 \%)$ \\
\hline Race, White (\%) & $49(65.3 \%)$ & $50(66.7 \%)$ & $66(88.0 \%)$ & $63(84.0 \%)$ \\
\hline BMI $\left(\mathrm{kg} / \mathrm{m}^{2}\right)$ & $28.4(5.5)$ & $28.3(4.6)$ & $27.8(4.0)$ & $26.6(4.8)$ \\
\hline Smoking Pack-years & $0(0)$ & $40.6(17.5)$ & $49.8(22.4)$ & $56.5(21.9)$ \\
\hline Hypertension (\%) & $24(32 \%)$ & $31(41.3 \%)$ & $42(56 \%)$ & $40(53.3 \%)$ \\
\hline Diabetes mellitus (\%) & $4(5.3 \%)$ & $10(13.3 \%)$ & $19(25.3 \%)$ & $10(13.3 \%)$ \\
\hline $\mathrm{FEV}_{1}(\mathrm{~L})$ & $3.06(0.69)$ & $3.24(0.71)$ & $2.79(0.62)$ & $1.23(0.26)$ \\
\hline $\mathrm{FEV}_{1} \%$ pred & $102.2(12.1)$ & $101.1(11.2)$ & $87.0(15.8)$ & $39.8(8.1)$ \\
\hline FVC (L) & $3.76(0.90)$ & $4.18(0.92)$ & $4.46(0.90)$ & $3.20(0.76)$ \\
\hline FVC \%pred & $97.8(11.1)$ & $99.9(11.1)$ & $104.9(15.6)$ & $77.5(14.4)$ \\
\hline $\mathrm{FEV}_{1} / \mathrm{FVC}$ & $0.82(0.05)$ & $0.78(0.05)$ & $0.62(0.06)$ & $0.39(0.09)$ \\
\hline Percentage Emphysema & $1.6(1.7)$ & $2.0(1.8)$ & $5.2(5.1)$ & $17.6(11.4)$ \\
\hline $\mathrm{Pi} 10$ & $3.67(0.09)$ & $3.68(0.07)$ & $3.70(0.08)$ & $3.74(0.08)$ \\
\hline CAC & $2.0(2.8)$ & $3.6(3.5)$ & $6.5(4.2)$ & $6.5(4.0)$ \\
\hline Statins $^{a}(\%)$ & $19(25.3 \%)$ & $25(33.3 \%)$ & $45(60.0 \%)$ & $32(42.7 \%)$ \\
\hline \multicolumn{5}{|l|}{ Centrilobular Emphysema (\%) } \\
\hline Mild (yes/no) (\%) & $3(4 \%)$ & $13(17.3 \%)$ & $20(26.7 \%)$ & $8(10.7 \%)$ \\
\hline Moderate (yes/no) (\%) & $0(0 \%)$ & $4(5.3 \%)$ & $21(28 \%)$ & $22(29.3 \%)$ \\
\hline Advanced/Confluent (yes/no) (\%) & $0(0 \%)$ & $4(5.3 \%)$ & $17(22.7 \%)$ & $42(56 \%)$ \\
\hline Substantial Paraseptal Emphysema (yes/no) (\%) & $0(0 \%)$ & $10(13.3 . \%)$ & $16(21.3 \%)$ & $13(17.3 \%)$ \\
\hline Definite Bronchial Wall Thickening (yes/no) (\%) & $0(0 \%)$ & $5(6.7 \%)$ & $17(22.7 \%)$ & $29(38.7 \%)$ \\
\hline
\end{tabular}

All values shown as mean (standard deviation) unless otherwise stated

FEV 1 Forced expiratory volume in the first second, FVC Forced vital capacity, CAC Coronary artery calcification, Pi10 Square root of the wall area of a theoretical circular cross section of an airway with $10 \mathrm{~mm}$ lumenal perimeter

Stratum $1=$ Lifetime non-smokers

Stratum 2 = Smokers without airflow obstruction. $\mathrm{FEV}_{1} / \mathrm{FVC} \geq 0.70$

Stratum $3=$ Mild to moderate airflow obstruction. $\mathrm{FEV}_{1} / \mathrm{FVC}<0.70, \mathrm{FEV}_{1} \geq 50 \%$ predicted

Stratum $4=$ Severe to very severe airflow obstruction. FEV $1 / F V C<0.70, \mathrm{FEV}_{1}<50 \%$ predicted

${ }^{a}$ Medication data displayed for usage in the three months prior to enrollment 
Table 2 Associations of Chronic Obstructive Pulmonary Disease with Coronary Artery Calcium ${ }^{\mathrm{a}}$

\begin{tabular}{|c|c|c|c|c|}
\hline & Univariate & & Multivariable $^{\mathrm{b}}$ & \\
\hline & $\beta$ estimate \pm SE & $p$ value & $\beta$ estimate \pm SE & $p$ value \\
\hline $\mathrm{FEV}_{1} / \mathrm{FVC}$ & $-0.723 \pm 0.006$ & $<0.001$ & $-0.192 \pm 0.093$ & 0.039 \\
\hline Log Emphysemac $^{c}$ & $0.348 \pm 0.064$ & $<0.001$ & $-0.075 \pm 0.076$ & 0.326 \\
\hline Pi10 & $0.841 \pm 0.207$ & $<0.001$ & $0.049 \pm 0.214$ & 0.819 \\
\hline Centrilobular Emphysema & $0.245 \pm 0.034$ & $<0.001$ & $0.073 \pm 0.036$ & 0.042 \\
\hline Paraseptal Emphysema & $0.102 \pm 0.052$ & 0.050 & $0.031 \pm 0.039$ & 0.429 \\
\hline Airway Wall Thickening & $0.195 \pm 0.046$ & $<0.001$ & $0.059 \pm 0.037$ & 0.112 \\
\hline
\end{tabular}

FEV 1 Forced expiratory volume in the first second, FVC Forced vital capacity. Pi10 Square root of the wall area of a theoretical circular cross section of an airway with $10 \mathrm{~mm}$ lumenal perimeter

${ }^{a}$ Coronary artery calcification log transformed. Separate models run for association between CAC and each subtype of chronic obstructive pulmonary disease

${ }^{\mathrm{b}}$ Model adjusted for age, sex, race, BMI, smoking status, pack-years, FEV ${ }_{1}$, hypertension, diabetes mellitus, statin use, and CT scanner type, except model for $\mathrm{FEV}_{1} / \mathrm{FVC}$ where $\mathrm{FEV}_{1}$ was not included

${ }^{\mathrm{C}}$ Assessed by percentage of low attenuation areas $<-950 \mathrm{HU}$ on quantitative $\mathrm{CT}$ using density mask analysis

univariate analysis, but this association was no longer significant after multivariable adjustments (Table 2).

\section{Visual analysis of COPD subtypes}

We found a significant association between log CAC and substantial CLE (adjusted $\beta=0.084 \pm 0.036 ; p=0.019$ ) but not paraseptal emphysema on multivariable analysis (Table 2). Although there was a significant association between definite airway wall thickening and $\log \mathrm{CAC}$ on univariate association, this association was no longer significant after multivariable adjustment (Table 2).

\section{Plasma biomarkers}

Additional file 1: Table S1 shows the mean (SD) values for the ten preselected biomarkers across the range of normal and disease severity. Most of the selected biomarkers increased with severity of lung disease, except CXCL5 which was lower in those with more severe airflow obstruction. Additional file 1: Table S2 shows that multiple plasma mediators correlated significantly with both CAC and emphysema (CRP, fibrinogen, MMP3, CXCL9 and VCAM1). CXCL5 correlated inversely with both CAC and emphysema. Additional file 1: Table S3 shows comparisons of biomarkers between those with and without each visual subtype of COPD. Multiple biomarkers were substantially higher in those with substantial CLE than in those without CLE, whereas there were no differences in biomarkers by substantial PSE status.

\section{Mediation analysis}

Table 3 shows the results of mediation analyses. We found a partial mediation effect for MMP3, VCAM1, CXCL5 and CXCL9 for the association between FEV 1 /FVC and $\log \mathrm{CAC}$, and these biomarkers partially mediated approximately $8,8,7$ and $16 \%$ of the effect, respectively. As $\log$ CAC was associated with substantial centrilobular emphysema, but not airway wall thickening, paraseptal emphysema, or overall quantitative emphysema, we repeated mediation analysis for the link between substantial CLE and log CAC. We found a partial mediation

Table 3 Plasma Mediators of the Association between Chronic Obstructive Pulmonary Disease and Coronary Artery Calcification

\begin{tabular}{|c|c|c|c|c|c|}
\hline Mediator $^{a}$ & Indirect Effect & $\begin{array}{l}\text { Bootstrap Bias Corrected 95\% Cl } \\
\text { for Indirect Effect }\end{array}$ & Direct Effect & $\%$ Effect Mediated & Sobel $p$-value \\
\hline \multicolumn{6}{|c|}{ A. Airflow obstruction $\left(\mathrm{FEV}_{1} / \mathrm{FVC}\right)$ and $\mathrm{CAC}$} \\
\hline MMP3 (ng/mL) & -0.061 & -0.126 to -0.022 & -0.662 & 8.5 & 0.015 \\
\hline VCAM1 (ng/mL) & -0.057 & -0.134 to -0.020 & -0.666 & 7.9 & 0.019 \\
\hline CXCL9 (pg/mL) & -0.114 & -0.194 to -0.057 & -0.609 & 15.8 & $<0.001$ \\
\hline CXCL5 (ng/mL) & -0.049 & -0.102 to -0.015 & -0.673 & 6.8 & 0.040 \\
\hline \multicolumn{6}{|c|}{ B. Centrilobular Emphysema and CAC } \\
\hline MMP3 (ng/mL) & 0.019 & 0.006 to 0.042 & 0.226 & 7.9 & 0.033 \\
\hline VCAM1 (ng/mL) & 0.018 & 0.004 to 0.041 & 0.227 & 7.3 & 0.041 \\
\hline CXCL9 $(p g / m L)$ & 0.042 & 0.022 to 0.074 & 0.203 & 17.0 & 0.001 \\
\hline
\end{tabular}

CAC Coronary artery calcification, FEV 1 Forced expiratory volume in the first second, FVC Forced vital capacity, MMP3 Matrix metalloproteinase 3 . VCAM1 = Vascular cell adhesion molecule 1. $\mathrm{CXCL}=\mathrm{C}-\mathrm{X}-\mathrm{C}$ Motif Chemokine Ligand

${ }^{a}$ All mediators were log transformed prior to analysis 
effect for three of the same plasma biomarkers important in the association between $\mathrm{FEV}_{1} / \mathrm{FVC}$ and $\log \mathrm{CAC}$ : MMP3, VCAM1 and CXCL9, for the association between substantial CLE and log CAC. Approximately 8, 7 and $17 \%$ of the total effect of substantial CLE on log CAC was partially mediated by MMP3, VCAM1 and CXCL9, respectively. As the association between airway wall thickening and $\log \mathrm{CAC}$ approached statistical significance, we repeated mediation models for this association. None of the plasma biomarkers mediated this association.

\section{Discussion}

In a cohort of healthy non-smokers and COPD patients with a range of disease severity, we found a significant relationship between airflow obstruction and the severity of coronary artery calcification but no association with structural correlates on quantitative CT imaging. The association between airflow obstruction and coronary calcification appears to be driven primarily by the centrilobular subtype of emphysema, and is linked through the same mediators, common bioactive molecules implicated in the pathogenesis of atherosclerosis.

There is growing awareness that COPD is a pro-atherosclerotic condition with an attributable risk comparable to other chronic inflammatory conditions such as rheumatoid arthritis, as well as other traditional cardiac risk factors such as diabetes mellitus and hypertension $[1,2$, 29]. We found that airflow obstruction is associated with the severity of $\mathrm{CAC}$, a finding that supports previous epidemiologic studies showing a higher frequency of coronary artery disease and greater burden of coronary calcification in COPD $[8,9,30,31]$. Although there appears to be a dose-response relationship between airflow obstruction and cardiac disease, previous studies such as the Evaluation of COPD Longitudinally to Identify Predictive Surrogate End-points (ECLIPSE) and the Multi-Ethnic Study of Atherosclerosis (MESA) have not found a relationship between the structural correlates of COPD such as emphysema and coronary calcification [32, 33]. We found a similar discordance with a relationship between airflow obstruction and CAC, but not between quantitative measures of structural lung disease and CAC. This has been a perplexing finding given the known relationship between airflow obstruction and CAC. There is however significant disagreement between quantitative emphysema and visual emphysema subtypes and visual subtypes offer prognostic additional information over quantitative measures [34]. We extend the literature by reporting that although overall emphysema and airway disease are not associated with CAC, the centrilobular subtype of emphysema, but not paraseptal emphysema or airway wall thickness, is independently associated with CAC.
The mediators of the link between airflow obstruction and coronary artery disease are not clear, and systemic inflammation has been commonly implicated in the pathogenesis of cardiac disease, mostly based on data from other chronic inflammatory conditions [13]. The correlations reported between inflammatory markers and measures of atherosclerosis in COPD are either modest or non-significant $[6,7,15,32,35-37]$. These previous studies were not designed to examine three-way relationships between COPD, cardiac disease and systemic inflammation. We identified a number of biomarkers that mediate the link between airflow obstruction and $\mathrm{CAC}$, and found that the mediators of the link between centrilobular emphysema and CAC were mostly similar. Similar to previous studies showing weak links between CAC and non-specific markers of inflammation such as CRP and fibrinogen in COPD, we did not find any mediator effect for these biomarkers. Matrix metalloproteinases are implicated in the pathogenesis of both emphysema and coronary atherosclerosis. MMP3 is present and enzymatically active in coronary plaques, and MMP3 polymorphisms are associated with the initiation and progression of these plaques, with plaque instability as well as with coronary calcification [38-40]. Matrix metalloproteinases 1 and 9 are important in the stability of the extracellular matrix in various tissues including the lung; however the role of MMP3 in the pathogenesis of emphysema is less clear. Recent studies have suggested that MMP3 polymorphisms are also important in the pathogenesis and severity of emphysema [41, 42]. Soluble adhesion molecules are involved in recruitment of macrophages and neutrophils, are involved in the transendothelial migration of these inflammatory cells, and circulating levels are higher in COPD patients than in healthy non-smokers [43]. VCAM1 but not ICAM1 has been implicated in the early pathogenesis of atherosclerotic plaques, via promotion of monocyte adhesion and accumulation on vessel walls susceptible to developing atherosclerosis [44]. Circulating VCAM is associated with greater CAD risk in other chronic inflammatory conditions such as type 2 diabetes mellitus $[45,46]$. CXCL9, a chemokine, is a T-cell chemoattractant that is induced by IFN- $\gamma$, and levels of CXCL9 are greater in sputum of COPD patients, and these levels correlate with disease severity [47]. CXCL9 and other CXCR3 chemokines have been implicated in the regulation of migration of monocytes and lymphocytes and their retention in atherosclerotic lesions, and serum levels of CXCL9 correlate with severity of coronary narrowing as well as coronary artery calcification $[48,49]$. Although mediation analysis cannot establish causality, and it is possible that systemic elevation of these biomarkers may just reflect progressive atherosclerosis, results of the mediation analyses suggest that they may have bioactive properties that are important in the pathogenesis 
of cardiovascular disease specifically in COPD. CXCL5 decreased with worsening severity of airflow obstruction. Recent data show that contrary to the other chemokines, CXCL5 may facilitate cholesterol efflux from macrophages and by reducing macrophage foam cell formation, have a protective role in atherogenesis [50].

Our study has several strengths. Participants in this cohort are well characterized with extensive phenotyping using CT and spirometry and a wide array of biomarkers. We included normal controls as well as participants with a wide range of airflow obstruction. The study also has some limitations. Although we selected ten potential mediators based on biologic plausibility and prior evidence, we may have missed other potential mediators; however, we did not include all available biomarkers so as to not overfit the models and to avoid false positive discovery. The inter-rater agreement for centrilobular emphysema was excellent and fair for paraseptal emphysema and bronchial wall thickening; however, we also used Pi10 to quantify airway disease. These rates of agreement for bronchial wall thickening are comparable to those observed in previous studies [51, 52]. Our associations are cross-sectional, and although temporal associations with acute events are an alternate model, these models would miss a substantial number of subclinical disease. Information on comorbidities such as diabetes mellitus and hypertension were ascertained from the participants as self-reported physician diagnoses but not confirmed with medical records. Although we selected participants randomly, there was a preponderance of male participants in the study and this may limit the generalizability of our findings. Finally, although mediation analyses were performed, we do not attribute causality and more research is needed to confirm these biologic pathways.

\section{Conclusions}

Chronic obstructive pulmonary disease is associated with coronary artery calcification, and the association is mainly driven by the centrilobular emphysema subtype. We found that inflammatory biomarkers involved in coronary atherosclerosis are elevated in those with COPD, especially with centrilobular emphysema, and mediate the link between emphysema and coronary artery calcification.

\section{Additional file}

Additional file 1: Supplemental Information. (DOCX 73 kb)

\section{Abbreviations}

BMl: Body mass index; CAC: Coronary artery calcification; CAD: Coronary artery disease; CLE: Centrilobular emphysema; COPD: Chronic obstructive pulmonary disease; CRP: C-reactive protein (CRP); CT: Computed tomography; CXCL: C-X-C Motif Chemokine Ligand; FEV1: Forced expiratory volume in the first second; FVC: Forced vital capacity; HU: Hounsfield Unit; ICAM: Intercellular adhesion molecule; IL-6: Interleukin-6; MMP: Matrix metalloproteinase; Pi10: Square root of the wall area of a theoretical circular cross section of an airway with $10 \mathrm{~mm}$ lumenal perimeter; PSE: Paraseptal emphysema; TNF-a: Tumor necrosis factor-alpha; VCAM: Vascular cell adhesion molecule

\section{Acknowledgements}

The authors thank the SPIROMICS participants and participating physicians, investigators and staff for making this research possible. More information about the study and how to access SPIROMICS data is at www.spiromics.org. We would like to acknowledge the following current and former

investigators of the SPIROMICS sites and reading centers: Neil E Alexis, PhD; Wayne H Anderson, PhD; R Graham Barr, MD, DrPH; Eugene R Bleecker, MD; Richard C Boucher, MD; Russell P Bowler, MD, PhD; Elizabeth E Carretta, MPH; Stephanie A Christenson, MD; Alejandro P Comellas, MD; Christopher B Cooper, MD, PhD; David J Couper, PhD; Gerard J Criner, MD; Ronald G Crystal, MD; Jeffrey L Curtis, MD; Claire M Doerschuk, MD; Mark T Dransfield, MD; Christine M Freeman, PhD; MeiLan K Han, MD, MS; Nadia N Hansel, MD, MPH; Annette T Hastie, PhD; Eric A Hoffman, PhD; Robert J Kaner, MD; Richard E Kanner, MD; Eric C Kleerup, MD; Jerry A Krishnan, MD, PhD; Lisa M LaVange, PhD; Stephen C Lazarus, MD; Fernando J Martinez, MD, MS; Deborah A Meyers, PhD; Wendy C Moore, MD; John D Newell Jr., MD; Laura Paulin, MD, MHS; Stephen Peters, MD, PhD; Elizabeth C Oelsner, MD, MPH; Wanda K O'Neal, PhD; Victor E Ortega, MD, PhD; Robert Paine, III, MD; Nirupama Putcha, MD, MHS; Stephen I. Rennard, MD; Donald P Tashkin, MD; Mary Beth Scholand, MD; J Michael Wells, MD; Robert A Wise, MD; and Prescott G Woodruff, MD, MPH. The project officers from the Lung Division of the National Heart, Lung, and Blood Institute were Lisa Postow, PhD, and Thomas Croxton, PhD, MD. SPIROMICS was supported by contracts from the NIH/NHLBI (HHSN268200900013C, HHSN268200900014C, HHSN268200900015C, HHSN268200900016C, HHSN268200900017C, HHSN268200900018C, HHSN268200900019C, HHSN268200900020C), and supplemented by contributions made through the Foundation for the $\mathrm{NIH}$ and the COPD Foundation from AstraZeneca/Medlmmune; Bayer; Bellerophon Therapeutics; Boehringer-Ingelheim Pharmaceuticals, Inc..; Chiesi Farmaceutici S.p.A.; Forest Research Institute, Inc.; GlaxoSmithKline; Grifols Therapeutics, Inc.; Ikaria, Inc.; Nycomed GmbH; Takeda Pharmaceutical Company; Novartis Pharmaceuticals Corporation; ProterixBio; Regeneron Pharmaceuticals, Inc.; Sanofi; and Sunovion.

\section{Funding}

This study was supported by NHLBI grant K23HL133438 to SPB. SPIROMICS was supported by contracts from the NIH/NHLBI (HHSN268200900013C, HHSN268200900014C, HHSN268200900015C, HHSN268200900016C, HHSN268200900017C, HHSN268200900018C, HHSN268200900019C, HHSN268200900020C), and supplemented by contributions made through the Foundation for the $\mathrm{NIH}$ and the COPD Foundation from AstraZeneca/ MedImmune; Bayer; Bellerophon Therapeutics; Boehringer-Ingelheim Pharmaceuticals, Inc..; Chiesi Farmaceutici S.p.A.; Forest Research Institute, Inc.; GlaxoSmithKline; Grifols Therapeutics, Inc.; Ikaria, Inc.; Nycomed GmbH; Takeda Pharmaceutical Company; Novartis Pharmaceuticals Corporation; ProterixBio; Regeneron Pharmaceuticals, Inc.; Sanofi; and Sunovion.

\section{Availability of data and materials}

SPIROMICS data is available on dbgap, and more details can be provided on request.

\section{Authors' contributions}

Study design: SPB and HN. Acquisition of data: All authors. Measurement of Emphysema and CAC: SPB, HN, JRW, NLJT and SS. Statistical analyses: SPB, YK and RR. Data interpretation: All authors. Manuscript writing: SPB and MTD. Critical review of the manuscript for important intellectual content: All authors. SPB had full access to all of the data in the study and takes responsibility for the integrity of the data and accuracy of the analysis. All authors read and approved the final manuscript.

Ethics approval and consent to participate

All participants signed a written informed consent form, and the Institutional Review Boarsd of all participating centers approved the study. 


\section{Competing interests}

SPB received funding from the NIH (K23HL133438); MKH reports personal fees from GSK, personal fees from Bl, personal fees from AstraZeneca, nonfinancial support from Novartis, non-financial support from Sunovion; MTD reports grants from NHLBl, during the conduct of the study; grants from Department of Defense, personal fees and other from Boehringer Ingeheim, personal fees and other from GlaxoSmithKline, other from Novartis, personal fees and other from AstraZeneca, other from Yungjin, other from PneumRx/ BTG, other from Pulmonx, personal fees from Genentech, personal fees and other from Boston Scientific; NLJT reports stocks in GE, CVS Caremark Corp, Johnson and Johnson, Pfizer, and Kimberley-Clark; PGW reports personal fees from Astra Zeneca, grants from Medimmune, personal fees from Regeneron, personal fees from Sanofi, personal fees from Genentech, personal fees from Janssen; JMW reports grants from NIH/NHLBI, grants and other from GSK, grants from AstraZeneca, other from Quintiles, other from Mylan, other from Gilead, grants from Bayer, grants from Cystic Fibrosis Foundation, other from Mereo Biopharma; RGB reports grants from $\mathrm{NIH}$, grants from Foundation for the $\mathrm{NIH}$, grants from COPD Foundation, during the conduct of the study; grants from Alpha1 Foundation, personal fees from UpToDate; HN, YK, RR, JRW, SS, $S P D, E C O, S B$ and WWL have no conflicts of interest to declare. Funding.

\section{Publisher's Note}

Springer Nature remains neutral with regard to jurisdictional claims in published maps and institutional affiliations.

\section{Author details}

${ }^{1}$ Division of Pulmonary, Allergy and Critical Care Medicine and Lung Health Center, University of Alabama at Birmingham, THT 422, 1720, 2nd Avenue South, Birmingham, AL 35294, USA. ${ }^{2}$ UAB Lung Imaging Core, University of Alabama at Birmingham, Birmingham, AL 35294, USA. ${ }^{3}$ Department of Radiology, University of Alabama at Birmingham, Birmingham, AL 35294, USA. ${ }^{4}$ Department of Preventive Medicine, University of Alabama at Birmingham, Birmingham, AL 35294, USA. ${ }^{5}$ Division of Pulmonary, Critical Care, Allergy and Sleep Medicine, University California San Francisco, San Francisco, CA 94143, USA. 'Birmingham Veterans Affairs Hospital, Birmingham, AL 35294, USA. ${ }^{7}$ Division of Pulmonary, Allergy and Critical Care Medicine, Columbia University Medical Center, New York, NY 10032, USA. ${ }^{8}$ Division of Pulmonary and Critical Care Medicine, University of Michigan, Ann Arbor, Ml 48109, USA. ${ }^{9}$ Division of Pulmonary and Critical Care Medicine, Weill Cornell School of Medicine, New York, NY 10065, USA.

Received: 5 July 2018 Accepted: 20 November 2018 Published online: 18 December 2018

\section{References}

1. Bhatt SP, Dransfield MT. Chronic obstructive pulmonary disease and cardiovascular disease. Transl Res. 2013;162(4):237-51.

2. Chen W, Thomas J, Sadatsafavi M, FitzGerald JM. Risk of cardiovascular comorbidity in patients with chronic obstructive pulmonary disease: a systematic review and meta-analysis. Lancet Respir Med. 2015;3(8):631-9.

3. Van Eeden S, Leipsic J, Paul Man SF, Sin DD. The relationship between lung inflammation and cardiovascular disease. Am J Respir Crit Care Med. 2012; 186(1):11-6.

4. Barr RG, Mesia-Vela S, Austin JH, Basner RC, Keller BM, Reeves AP, et al. Impaired flow-mediated dilation is associated with low pulmonary function and emphysema in ex-smokers: the emphysema and Cancer action project (EMCAP) study. Am J Respir Crit Care Med. 2007; 176(12):1200-7.

5. Lahousse L, van den Bouwhuijsen QJ, Loth DW, Joos GF, Hofman A, Witteman JC, et al. Chronic obstructive pulmonary disease and lipid core carotid artery plaques in the elderly: the Rotterdam study. Am J Respir Crit Care Med. 2013;187(1):58-64.

6. McAllister DA, Maclay JD, Mills NL, Mair G, Miller J, Anderson D, et al. Arterial stiffness is independently associated with emphysema severity in patients with chronic obstructive pulmonary disease. Am J Respir Crit Care Med. 2007;176(12):1208-14.

7. Sabit R, Bolton CE, Edwards PH, Pettit RJ, Evans WD, McEniery CM, et al. Arterial stiffness and osteoporosis in chronic obstructive pulmonary disease. Am J Respir Crit Care Med. 2007;175(12):1259-65.
8. O'Hare PE, Ayres JF, O'Rourke RL, Slaughter RE, Marshall HM, Bowman RV, et al. Coronary artery calcification on computed tomography correlates with mortality in chronic obstructive pulmonary disease. J Comput Assist Tomogr. 2014;38(5):753-9.

9. Chandra D, Gupta A, Strollo PJ Jr, Fuhrman CR, Leader JK, Bon J, et al. Airflow limitation and endothelial dysfunction. Unrelated and independent predictors of atherosclerosis. Am J Respir Crit Care Med. 2016;194(1):38-47.

10. Eickhoff P, Valipour A, Kiss D, Schreder M, Cekici L, Geyer K, et al. Determinants of systemic vascular function in patients with stable chronic obstructive pulmonary disease. Am J Respir Crit Care Med. 2008;178(12): $1211-8$.

11. Moro L, Pedone C, Scarlata S, Malafarina V, Fimognari F, Antonelli-Incalzi R. Endothelial dysfunction in chronic obstructive pulmonary disease. Angiology. 2008:59(3):357-64.

12. Sin DD, Man SF. Chronic obstructive pulmonary disease as a risk factor for cardiovascular morbidity and mortality. Proc Am Thorac Soc. 2005; 2(1):8-11

13. Mason JC, Libby P. Cardiovascular disease in patients with chronic inflammation: mechanisms underlying premature cardiovascular events in rheumatologic conditions. Eur Heart J. 2015;36(8):482-9c.

14. Omori H, Tsuji M, Sata K, lyonaga C, Narimatsu A, Mihara S, et al. Correlation of $\mathrm{C}$-reactive protein with disease severity in $\mathrm{CT}$ diagnosed emphysema. Respirology. 2009;14(4):551-8.

15. Papaioannou Al, Mazioti A, Kiropoulos T, Tsilioni I, Koutsokera A, Tanou K, et al. Systemic and airway inflammation and the presence of emphysema in patients with COPD. Respir Med. 2010;104(2):275-82.

16. Mills NL, Miller JJ, Anand A, Robinson SD, Frazer GA, Anderson D, et al, Increased arterial stiffness in patients with chronic obstructive pulmonary disease: a mechanism for increased cardiovascular risk. Thorax. 2008:63(4):306-11.

17. Couper D, LaVange LM, Han M, Barr RG, Bleecker E, Hoffman EA, et al. Design of the Subpopulations and Intermediate Outcomes in COPD study (SPIROMICS). Thorax. 2014;69(5):491-4.

18. Hecht HS, Cronin P, Blaha MJ, Budoff MJ, Kazerooni EA, Narula J, et al. 2016 SCCT/STR guidelines for coronary artery calcium scoring of noncontrast noncardiac chest CT scans: a report of the Society of Cardiovascular Computed Tomography and Society of thoracic radiology. J Cardiovasc Comput Tomogr. 2017;11(1):74-84.

19. Vogelmeier CF, Criner GJ, Martinez FJ, Anzueto A, Barnes PJ, Bourbeau J, et al. Global strategy for the diagnosis, management, and prevention of chronic obstructive lung disease 2017 report. GOLD executive summary. Am J Respir Crit Care Med. 2017;195(5):557-82.

20. Regan EA, Hokanson JE, Murphy JR, Make B, Lynch DA, Beaty TH, et al. Genetic epidemiology of COPD (COPDGene) study design. Copd. 2010; 7(1):32-43.

21. Sieren JP, Newell JD Jr, Barr RG, Bleecker ER, Burnette N, Carretta EE, et al. SPIROMICS protocol for multicenter quantitative computed tomography to phenotype the lungs. Am J Respir Crit Care Med. 2016; 194(7):794-806

22. Nakano Y, Muro S, Sakai H, Hirai T, Chin K, Tsukino M, et al. Computed tomographic measurements of airway dimensions and emphysema in smokers. Correlation with lung function. Am J Respir Crit Care Med. 2000; 162(3 Pt 1):1102-8.

23. Lynch DA, Austin JH, Hogg JC, Grenier PA, Kauczor HU, Bankier AA, et al. CT-definable subtypes of chronic obstructive pulmonary disease: a statement of the Fleischner society. Radiology. 2015;277(1):192-205.

24. O'Neal WK, Anderson W, Basta PV, Carretta EE, Doerschuk CM, Barr RG, et al. Comparison of serum, EDTA plasma and P100 plasma for luminex-based biomarker multiplex assays in patients with chronic obstructive pulmonary disease in the SPIROMICS study. J Transl Med. 2014;12:9.

25. Kirsch J, Buitrago I, Mohammed TL, Gao T, Asher CR, Novaro GM. Detection of coronary calcium during standard chest computed tomography correlates with multi-detector computed tomography coronary artery calcium score. Int J Cardiovasc Imaging. 2012;28(5):1249-56.

26. Watts JR DD Jr, Fineberg NS, Budoff M, Nath H. Correlation between measured and visual scoring of coronary artery calcification. Int J Cardiovasc Cerebrovasc Dis. 2014;2:11-7.

27. Baron RM, Kenny DA. The moderator-mediator variable distinction in social psychological research: conceptual, strategic, and statistical considerations. J Pers Soc Psychol. 1986;51(6):1173-82. 
28. Mackinnon DP, Lockwood CM, Williams J. Confidence limits for the indirect effect: distribution of the product and resampling methods. Multivar Behav Res. 2004;39(1):99.

29. Bhatt SP, Wells JM, Dransfield MT. Cardiovascular disease in COPD: a call for action. Lancet Respir Med. 2014;2(10):783-5.

30. Curkendall SM, DeLuise C, Jones JK, Lanes S, Stang MR, Goehring E Jr, et al. Cardiovascular disease in patients with chronic obstructive pulmonary disease, Saskatchewan Canada cardiovascular disease in COPD patients. Ann Epidemiol. 2006;16(1):63-70.

31. Finkelstein J, Cha E, Scharf SM. Chronic obstructive pulmonary disease as an independent risk factor for cardiovascular morbidity. Int J Chron Obstruct Pulmon Dis. 2009;4:337-49.

32. Williams MC, Murchison JT, Edwards LD, Agusti A, Bakke P, Calverley PM, et al. Coronary artery calcification is increased in patients with COPD and associated with increased morbidity and mortality. Thorax. 2014;69(8):718-23

33. Barr RG, Ahmed FS, Carr JJ, Hoffman EA, Jiang R, Kawut SM, et al. Subclinica atherosclerosis, airflow obstruction and emphysema: the MESA lung study. Eur Respir J. 2012;39(4):846-54

34. Lynch DA, Moore CM, Wilson C, Nevrekar D, Jennermann T, Humphries SM, Austin JHM, Grenier PA, Kauczor HU, Han MK, Regan EA, Make BJ, Bowler RP, Beaty TH, Curran-Everett D, Hokanson JE, Curtis JL, Silverman EK, Crapo JD; Genetic Epidemiology of COPD (COPDGene) Investigators. Radiology. 2018; 288(3):859-66. https://doi.org/10.1148/radiol.2018172294. Epub 2018 May 15.

35. Bhatt SP, Cole AG, Wells JM, Nath H, Watts JR, Cockcroft JR, et al. Determinants of arterial stiffness in COPD. BMC Pulm Med. 2014;14:1.

36. Kim SJ, Yoon DW, Lee EJ, Hur GY, Jung KH, Lee SY, et al. Carotid atherosclerosis in patients with untreated chronic obstructive pulmonary disease. Int J Tuberc Lung Dis. 2011;15(9):1265-70 i.

37. Janner JH, McAllister DA, Godtfredsen NS, Prescott E, Vestbo J. Is chronic obstructive pulmonary disease associated with increased arterial stiffness? Respir Med. 2012;106(3):397-405.

38. Pollanen PJ, Lehtimaki T, Ilveskoski E, Mikkelsson J, Kajander OA, Laippala P et al. Coronary artery calcification is related to functional polymorphism of matrix metalloproteinase 3: the Helsinki sudden death study. Atherosclerosis. 2002;164(2):329-35.

39. Wang J, Xu D, Wu X, Zhou C, Wang H, Guo Y, et al. Polymorphisms of matrix metalloproteinases in myocardial infarction: a meta-analysis. Heart. 2011;97(19):1542-6.

40. Beyzade S, Zhang S, Wong YK, Day IN, Eriksson P, Ye S. Influences of matrix metalloproteinase-3 gene variation on extent of coronary atherosclerosis and risk of myocardial infarction. J Am Coll Cardiol. 2003:41(12):2130-7.

41. McAloon CJ, Wood AM, Gough SC, Stockley RA. Matrix metalloprotease polymorphisms are associated with gas transfer in alpha 1 antitrypsin deficiency. Ther Adv Respir Dis. 2009;3(1):23-30.

42. Hobbs BD, Parker MM, Chen H, Lao T, Hardin M, Qiao D, et al. Exome Array analysis identifies a common variant in IL27 associated with chronic obstructive pulmonary disease. Am J Respir Crit Care Med. 2016;194(1):48-57.

43. Blidberg K, Palmberg L, James A, Billing B, Henriksson E, Lantz AS, et al. Adhesion molecules in subjects with COPD and healthy non-smokers: a cross sectional parallel group study. Respir Res. 2013;14:47.

44. Cybulsky MI, liyama K, Li H, Zhu S, Chen M, liyama M, et al. A major role for VCAM1, but not ICAM-1, in early atherosclerosis. J Clin Invest. 2001;107(10):1255-62.

45. Jager A, van Hinsbergh WW, Kostense PJ, Emeis JJ, Nijpels G, Dekker JM, et al. Increased levels of soluble vascular cell adhesion molecule 1 are associated with risk of cardiovascular mortality in type 2 diabetes: the Hoorn study. Diabetes. 2000;49(3):485-91.

46. Otsuki M, Hashimoto K, Morimoto Y, Kishimoto T, Kasayama S. Circulating vascular cell adhesion molecule-1 (VCAM-1) in atherosclerotic NIDDM patients. Diabetes. 1997;46(12):2096-101.

47. Costa C, Rufino R, Traves SL, Lapa ESJR, Barnes PJ, Donnelly LE. CXCR3 and CCR5 chemokines in induced sputum from patients with COPD. Chest. 2008;133(1):26-33.

48. Liang Y, Yang C, Zhou Q, Pan W, Zhong W, Ding R, et al. Serum Monokine induced by gamma interferon is associated with severity of coronary artery disease. Int Heart J. 2017;58(1):24-9.

49. Yu HT, Oh J, Chang HJ, Lee SH, Shin EC, Park S. Serum monokine induced by gamma interferon as a novel biomarker for coronary artery calcification in humans. Coron Artery Dis. 2015;26(4):317-21.
50. Rousselle A, Qadri F, Leukel L, Yilmaz R, Fontaine JF, Sihn G, et al. CXCL5 limits macrophage foam cell formation in atherosclerosis. J Clin Invest. 2013; 123(3):1343-7.

51. Kim SS, Seo JB, Lee HY, Nevrekar DV, Forssen AV, Crapo JD, et al. Chronic obstructive pulmonary disease: lobe-based visual assessment of volumetric $\mathrm{CT}$ by using standard images--comparison with quantitative $C T$ and pulmonary function test in the COPDGene study. Radiology. 2013;266(2): 626-35.

52. COPDGene CT Workshop Group, Barr RG, Berkowitz EA, Bigazzi F, Bode F, Bon J, et al. A combined pulmonary-radiology workshop for visual evaluation of COPD: study design, chest CT findings and concordance with quantitative evaluation. Copd. 2012;9(2):151-9.

\section{Ready to submit your research? Choose BMC and benefit from:}

- fast, convenient online submission

- thorough peer review by experienced researchers in your field

- rapid publication on acceptance

- support for research data, including large and complex data types

- gold Open Access which fosters wider collaboration and increased citations

- maximum visibility for your research: over $100 \mathrm{M}$ website views per year

At $\mathrm{BMC}$, research is always in progress.

Learn more biomedcentral.com/submissions 